\title{
A Self-Calibrating Palmer Drought Severity Index
}

\author{
Nathan Wells and STEve Goddard \\ Computer Science and Engineering, University of Nebraska-Lincoln, Lincoln, Nebraska \\ Michael J. HAYeS \\ National Drought Mitigation Center, University of Nebraska-Lincoln, Lincoln, Nebraska
}

(Manuscript received 10 April 2003, in final form 9 January 2004)

\begin{abstract}
The Palmer Drought Severity Index (PDSI) has been used for more than 30 years to quantify the long-term drought conditions for a given location and time. However, a common critique of the PDSI is that the behavior of the index at various locations is inconsistent, making spatial comparisons of PDSI values difficult, if not meaningless.

A self-calibrating Palmer Drought Severity Index (SC-PDSI) is presented and evaluated. The SC-PDSI automatically calibrates the behavior of the index at any location by replacing empirical constants in the index computation with dynamically calculated values. An evaluation of the SC-PDSI at 761 sites within Nebraska, Kansas, Colorado, Wyoming, Montana, North Dakota, and South Dakota, as well as at all 344 climate divisions shows that it is more spatially comparable than the PDSI, and reports extreme wet and dry conditions with frequencies that would be expected for rare conditions.
\end{abstract}

\section{Introduction}

The Palmer Drought Severity Index (PDSI) (Palmer 1965) was one of the first procedures to demonstrate success at quantifying the severity of droughts across different climates. Palmer's objective was to "develop a general methodology for evaluating (the drought) in terms of an index that permits time and space comparisons of drought severity" (Palmer 1965). Instead of being based purely on precipitation, the PDSI is based upon a primitive water balance model. As detailed in section 2, the basis of the index is the difference between the amount of precipitation required to retain a normal water-balance level and the amount of actual precipitation. The other parts of the PDSI calculation account for climatic differences between locations and seasons of the year. These computations attempt to scale the index values so that they fit Palmer's 11 categories, shown in Table 1, and to allow for comparisons across time and space.

In the years since its development, the PDSI has become a standard for measuring meteorological drought, particularly in the United States. There have been many criticisms of the PDSI over the years, but perhaps one of the most common complaints is that PDSI values are not comparable between diverse climatological regions.

Corresponding author address: Steve Goddard, University of Nebraska-Lincoln, 215A Ferguson Hall, Lincoln, NE 68588-0115. E-mail: goddard@cse.unl.edu
The performance of the PDSI in the western United States has been particularly poor. This work addresses the spatial comparability problem identified by Karl (1983, 1986), Alley (1984), Heddinghaus and Sabol (1991), and Guttman et al. (1992).

Palmer calculated empirical constants for the climatic characteristic and the duration factors used in the computation of the PDSI, which directly affect the spatial comparability of the index, by averaging the values from only a few locations representing a small number of climates. These averaged values of the climatic characteristic and the duration factors have since become a fixed part of the calculations of the PDSI, regardless of the climate in which it is used. Advances in computing technology make it possible to improve the performance of the PDSI by dynamically replacing the averaged constants with values based on the characteristics of the local climate. This is achieved by correctly weighting the climatic characteristic, which affects the range of PDSI values, and the automatic calculation of the duration factors, which adjusts the sensitivity of the index. These two modifications cause the index to behave in a consistent, predictable manner as well as to more realistically represent the climates of diverse locations.

While the procedure presented here for calculating the PDSI is different from Palmer's original procedure, it does not stray from his objective. By simply automating the processes that Palmer used to derive the empirical constants used in his procedure, it does what 
TABLE 1. Classification of the PDSI values.

\begin{tabular}{ll}
\hline \hline \multicolumn{1}{c}{ PDSI value } & PDSI category \\
\hline Above 4.00 & Extreme wet spell \\
$3.00-3.99$ & Severe wet spell \\
$2.00-2.99$ & Moderate wet spell \\
$1.00-1.99$ & Mild wet spell \\
$0.50-0.99$ & Incipient wet spell \\
0.49 to -0.49 & Normal \\
-0.50 to -0.99 & Incipient drought \\
-1.00 to -1.99 & Mild drought \\
-2.00 to -2.99 & Moderate drought \\
-3.00 to -3.99 & Severe drought \\
Below -4.00 & Extreme drought \\
\hline
\end{tabular}

Palmer might have done, had he been given access to today's computing resources. In a sense, the new procedure for calculating the PDSI is simply a modern implementation of Palmer's ideas. By following Palmer's example, a self-calibrating PDSI (SC-PDSI) has been created that will behave as he intended and, more importantly, as decision makers and researchers expect it to.

\section{A brief review of Palmer's procedure}

The procedure Palmer developed will be referred to many times throughout this study, so for the sake of convenience, an abbreviated explanation of his procedure has been included. The following explanation is based directly on Palmer's paper (Palmer 1965), which describes in detail how to calculate the PDSI using a 1-month time step.

Each month of every year, four values related to the soil moisture are computed along with their complementary potential values. These eight values are evapotranspiration (ET), recharge $(R)$, runoff (RO), loss $(L)$, potential evapotranspiration (PE), potential recharge (PR), potential runoff (PRO), and potential loss (PL). The potential evapotranspiration is estimated using Thornthwaite's method (Thornthwaite 1948). The calculation of these values depends heavily on the available water holding capacity (AWC) of the soil. The PDSI itself depends on a two-stage "bucket" model of the soil. The top layer of soil is assumed to hold one inch of moisture. The amount of moisture that can be held by the rest of the underlying soil is a location-dependent value, which must be provided as an input parameter to the program.

The four potential values are weighted according to the climate of the area using $\alpha, \beta, \gamma$, and $\delta$ to give the climatically appropriate for existing conditions (CAFEC) potential values. The weighting factors $\alpha, \beta, \gamma$, and $\delta$ are called the water-balance coefficients and are found in the following manner:

$$
\begin{aligned}
\alpha_{i}=\frac{\overline{\mathrm{ET}_{i}}}{\overline{\mathrm{PE}_{i}}} & \beta_{i}=\frac{\overline{R_{i}}}{\overline{\mathrm{PR}_{i}}} \\
\gamma_{i}=\frac{\overline{\mathrm{RO}_{i}}}{\overline{\mathrm{PRO}_{i}}} & \delta_{i}=\frac{\overline{L_{i}}}{\overline{\mathrm{PL}_{i}},}
\end{aligned}
$$

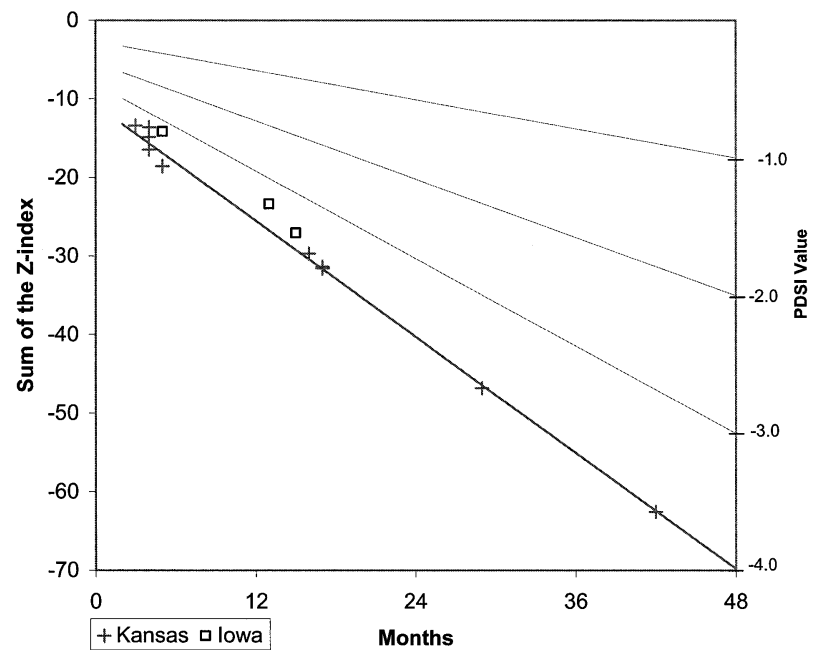

FIG. 1. Accumulated $Z$ index over the driest intervals of varying lengths from Palmer's Table 7 (Palmer 1965, p. 20). The overlying lines represent the PDSI values according to the accumulated $Z$ index. Redrawn from Palmer's (1965, p. 20) Fig. 1.

where $i$ ranges over the months of the year. The bar over a term indicates an average value. For example, the average loss is computed for January by

$$
\overline{L_{1}}=\frac{\sum_{\text {all years }} L_{1}}{\text { number of years of data }} .
$$

The CAFEC potential values are combined to form the CAFEC precipitation, $\hat{P}$, which represents the amount of precipitation needed to maintain a normal soil moisture level for a single month:

$$
\hat{P}=\alpha_{i} \mathrm{PE}+\beta_{i} \mathrm{PR}+\gamma_{i} \mathrm{PRO}-\delta_{i} \mathrm{PL} .
$$

The difference between the actual precipitation that fell in a specific month and the computed CAFEC precipitation is the moisture departure, denoted $d$ :

$$
d=P-\hat{P}=P-\left(\alpha_{i} \mathrm{PE}+\beta_{i} \mathrm{PR}+\gamma_{i} \mathrm{PRO}-\delta_{i} \mathrm{PL}\right) .
$$

The moisture departure, $d$, is the excess or shortage of precipitation compared to the CAFEC precipitation. Of course, the same $d$ will mean different things at different times, as well as at different locations. This prevents straightforward comparisons from being made between different values of $d$. To correct for this, the moisture departure is weighted using $K$, which is called the climatic characteristic. Here $K$ is actually a refinement of $K^{\prime}$, which is Palmer's general approximation for the climate characteristic of a location. Palmer derived Eqs. (1) and (2) for $K^{\prime}$ and for $K$, respectively, where $\bar{D}_{i}$ is the average moisture departure for the appropriate month: 

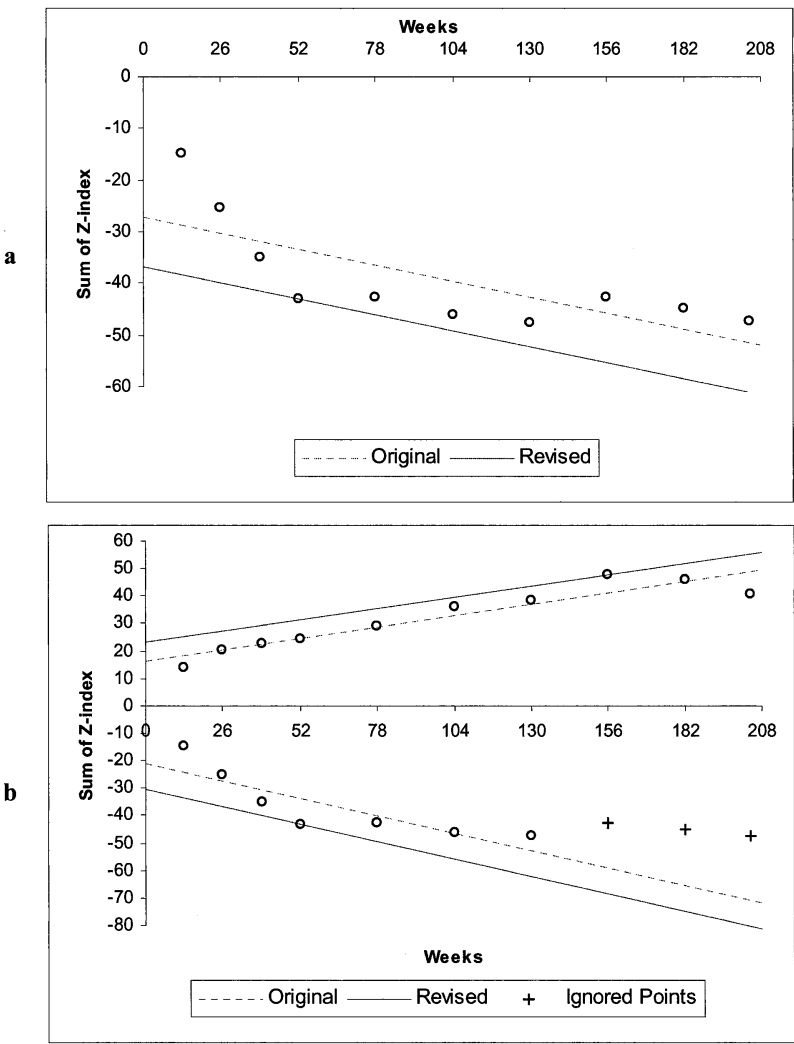

FIG. 2. (a) An example of poor linear correlation. Neither the original nor the revised line appears to fit the data. This particular figure shows only the dry periods. (b) The final lines used in calculating both the wet and dry duration factors. By ignoring the last three data points in the bottom portion, the regression lines fit the data better Data from the Nebraska station Sidney 6 NNW (1948-2001).

$$
\begin{aligned}
K_{i}^{\prime}= & 1.5 \log _{10}\left(\frac{\frac{\overline{\mathrm{PE}_{i}}+\overline{R_{i}}+\overline{\mathrm{RO}_{i}}+\overline{L_{i}}}{\overline{D_{i}}}+2.8}{\frac{\bar{P}_{i}}{K_{i}}=}\right)+0.5 \\
\sum_{j=1}^{12} \overline{D_{j}} K_{j}^{\prime} & K_{i}^{\prime} .
\end{aligned}
$$

The value of 17.67 in (2) is an empirical constant that Palmer derived using data from nine different locations in seven states (Palmer 1965). The purpose of the climatic characteristic, $K$, is to adjust the value of $d$ according to the characteristics of the climate in such a way as to allow for accurate comparisons of PDSI values over time and space.

The result of multiplying the moisture departure, $d$, by $K$ is called the moisture anomaly index, or the $Z$ index, and is denoted by $Z$, shown as

$$
Z=d K \text {. }
$$

The $Z$ index can be used to show how wet or dry it was during a single month without regard to recent precipitation trends. The $Z$ index is used to calculate the PDSI value for a given month using the general formula:

$$
X_{i}=0.897 X_{i-1}+\left(\frac{1}{3}\right) Z_{i} .
$$

For example, to calculate the current value of $X_{i}$, 0.897 times the previous PDSI value $X_{i-1}$ is added to one-third of the current moisture anomaly $Z_{i}$. Palmer called the values 0.897 and $1 / 3$ the duration factors. They were empirically derived by Palmer from two locations (western Kansas and central Iowa) and affect the sensitivity of the index to precipitation events.

Three PDSI values are actually computed each month: $X_{1}, X_{2}$, and $X_{3}$. The values of $X_{1}$ and $X_{2}$ are the severity of a wet or dry spell, respectively, that might become established. A spell becomes established when it reaches the threshold of \pm 0.5 . This threshold follows from the fact that index values between -0.5 and 0.5 are regarded as "normal" values; $X_{3}$ is the severity of a wet or dry spell that is currently established. If there is no established spell, the PDSI value is set to either $X_{1}$ or $X_{2}$, according to which spell is most likely to become established. This is determined by which index is closer to the threshold of an established spell, which is simply the index with a larger absolute value. If there is a current spell established, that is, when $X_{3}$ is not zero, the PDSI value for that month is $X_{3}$. However, when the index is calculated at a later date, it may be discovered that the current spell actually ended earlier. In this case, the PDSI values will be replaced by values of either $X_{1}$ or $X_{2}$. This replacement of previously calculated PDSI values will be referred to as backtracking. Exactly how backtracking works, and what factors set it off are beyond the scope of this study. However, the existence of backtracking means that a small change in how the indices are computed may cause backtracking, which has a substantial effect on the final values of the index.

\section{A method for calibrating the PDSI}

The SC-PDSI replaces the empirically derived climatic characteristic $(K)$ and duration factors $(0.897$ and $1 / 3$ ) with values automatically calculated based upon the historical climatic data of a location. This section explains how these values are computed as part of the SC-PDSI.

\section{a. Climatic characteristic}

The moisture departure, $d$, does not accurately reflect how and to what extent the lack (or excess) of moisture affects a region. To correct for this, the PDSI is based on the moisture anomaly, $Z$ (or $Z$ index), which is the product of the moisture departure and the climate characteristic, $K$, as shown in (3). The role of the climate characteristic is to correct for the natural aberrations that appear in the moisture departure due to the climate of the region and how it changes with the seasons. 


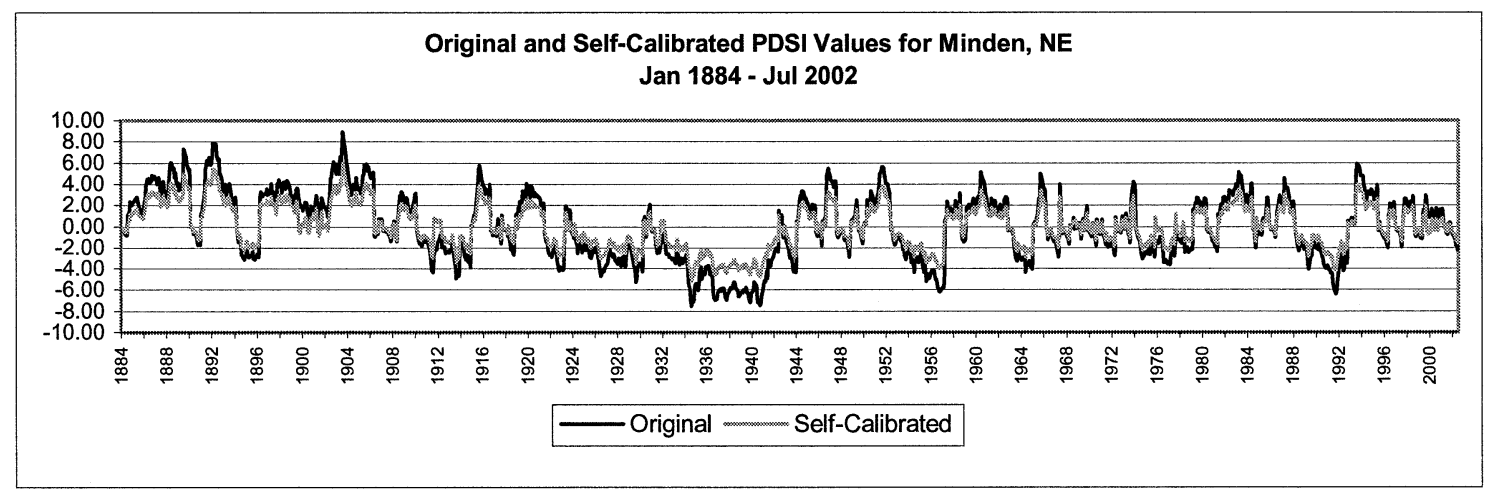

a

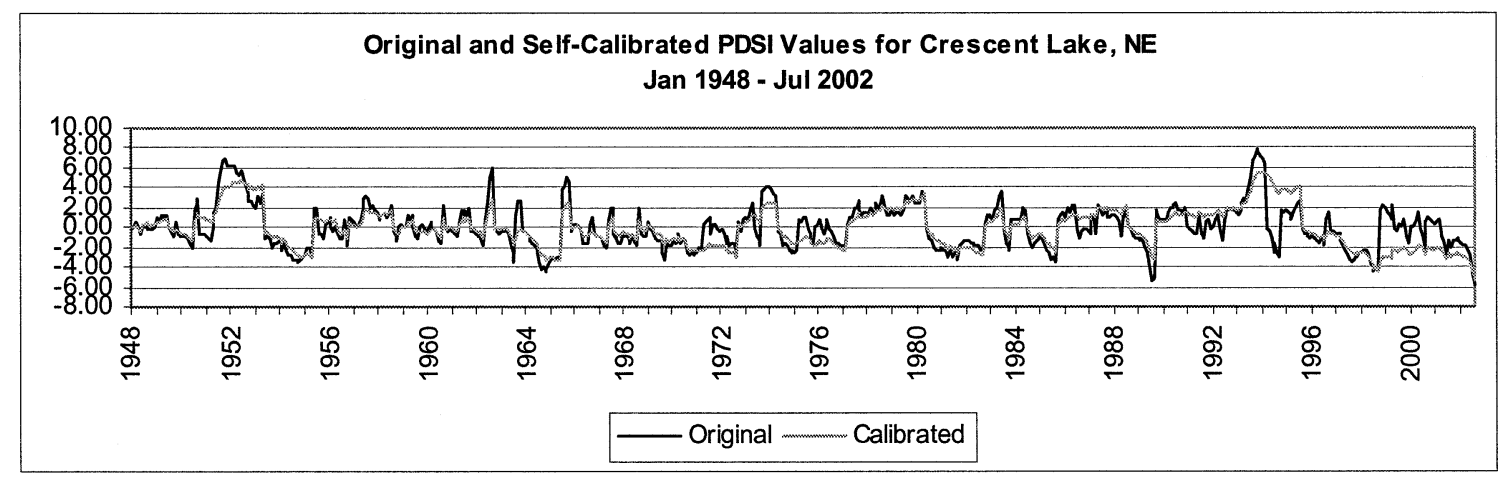

FIG. 3. Time series plots of the original PDSI and the SC-PDSI at (a) Minden, NE, from Jan 1884 to Jul 2002; and (b) Crescent Lake, NE, from Jan 1948 to Jul 2002.

There are two clear parts to (2), the first being the ratio $\tilde{K}$ and the second being $K^{\prime}$ of (1), where

$$
\tilde{K}=\frac{17.67}{\sum_{j=1}^{12}\left|\overline{d_{j}}\right| K_{j}^{\prime}} .
$$

The climate characteristic must vary over both time and space to account for the changes in the climate. Here $K^{\prime}$ approximates the average precipitation and conditions of the soil of each month, so it will vary from one month to the next. However, $\tilde{K}$ only varies over space. The criticisms of the PDSI have revolved around its inconsistencies from one location to the next, rather than over time at a single location. Altering the ratio shown in (5) addresses the spatial inconsistencies of the PDSI without changing the way it handles seasonal changes in the climate.

The denominator of (5) is the product of the average absolute value of the moisture departure $d$ and $K^{\prime}$, summed over the 12 months of the year. The product of $d$ and $K^{\prime}$ is a first-order approximation of the moisture anomaly $Z$ for a given month. Thus, the denominator of (5) can be viewed as an approximation of the annual sum of the average absolute value of $Z$ over a 12-month period. Let

$$
\tilde{Z}=\sum_{j=1}^{12}\left|\bar{d}_{j}\right| K_{j}^{\prime} .
$$

The numerator of (5), 17.67, is the average value of $\tilde{Z}$ shown in (6) using data from nine different climate divisions: three from Texas and one each from Kansas, Iowa, North Dakota, Ohio, Pennsylvania, and Tennessee. Thus, the ratio $\tilde{K}$ can be rewritten as the ratio of the expected value of $\tilde{Z}$ to the observed value of $\tilde{Z}$. If $\tilde{Z}$ is considered as the average annual sum of the moisture anomaly, then the PDSI itself can be used in its place since the PDSI is based on the accumulated moisture anomaly. This results in the following ratio:

$$
\tilde{K}=\frac{\text { expected average PDSI }}{\text { observed average PDSI }} \text {. }
$$

Equation (7) for $\tilde{K}$ has a major problem because one would expect the average PDSI value to be zero. Instead of using the central tendency of the PDSI distribution, as (7) does, its tails can be used. Palmer defined the range of nonextreme PDSI values to run from -4.00 to 4.00 . In practice, however, this range varies. If the PDSI really were a standardized measure of drought severity, then the frequency of values outside that range would be about the same. If this frequency of extreme events is defined 



FIG. 4. Plots showing the frequency of original and self-calibrated monthly PDSI values (a) over the entire range of PDSI values and (b) over the major PDSI categories for Minden, NE.

as some value, $f_{e}$, then the $f_{e}$ th percentile should be -4.00 and the $\left(100-f_{e}\right)$ th percentile should be 4.00 . This gives the following equation for $\tilde{K}$ :

$$
\tilde{K}=\left\{\begin{array}{l}
\frac{\text { expected } f_{e} \text { th percentile of the PDSI }}{\text { observed } f_{e} \text { percentile of the PDSI }} \\
\frac{\text { expected }\left(100-f_{e}\right) \text { th percentile of the PDSI }}{\text { observed }\left(100-f_{e}\right) \text { th percentile of the PDSI }}
\end{array}\right.
$$

The question remains of what value $f_{e}$ should be, which depends on how an "extreme" drought is defined. Defining extreme drought as a "one in 50 year event" does not determine what percentage of PDSI values should be below -4.00 because it could last for two months or two years. For this implementation, the value of $f_{e}$ used was $2 \%$, which gives the following equation for the climate characteristic:

$$
K= \begin{cases}K^{\prime}(-4.00 / 2 \text { nd percentile }), & \text { if } d<0 \\ K^{\prime}(4.00 / 98 \text { th percentile }), & \text { if } d \geq 0\end{cases}
$$

To calculate $K$, as it is defined in (9), the PDSI must first be calculated using $Z=d K^{\prime}$, where $K^{\prime}$ is computed using (1). After computing this first-order approximation of $Z$, the $2 \mathrm{~d}$ and 98 th percentile of PDSI values are used to compute $K$ with (9), and then the PDSI is recomputed.

The climatic characteristic, as it is defined in (9), is computed using the method that Palmer used but based on the definition of the index instead of an average value derived from a set of sites. This removes from the climatic characteristic, and therefore from the index itself, the dependence on the climatic conditions that were experienced at the nine locations used in Palmer's study. Instead, the climatic characteristic is based solely on how the climate of the location, namely the range of its moisture departures, $d$, is related to the defined range of the PDSI. This is reasonable because the climate characteristic is intended to map the moisture departures to the appropriate values of the $Z$ index such that the PDSI matches its defined behavior.

A side effect of this method is that the climate characteristic, and therefore the value of the index itself, is 

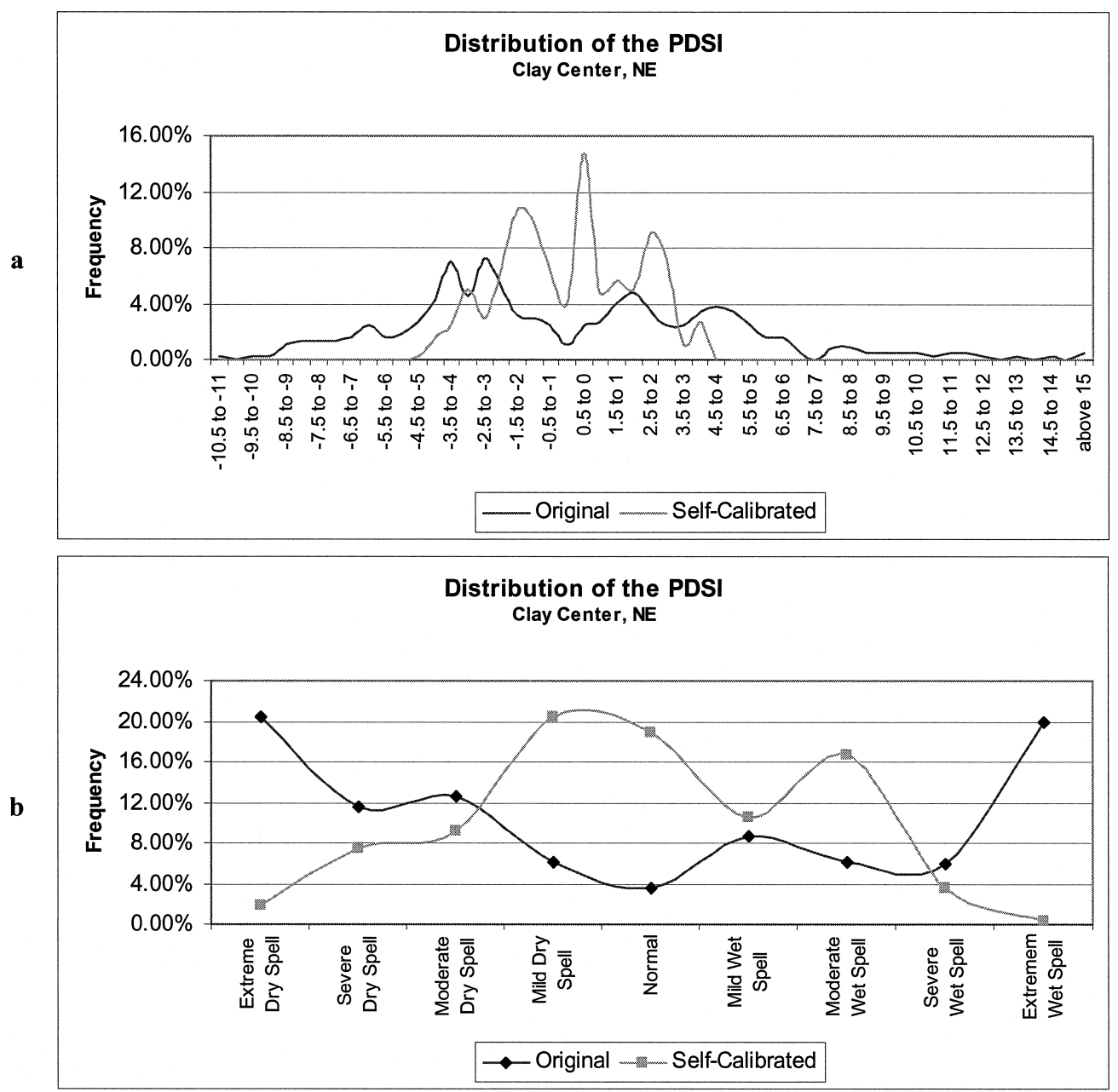

FIG. 5. Plots showing the frequency of original and self-calibrated monthly PDSI values (a) over the entire range of PDSI values and (b) over the major PDSI categories for Clay Center, NE.

now based on the historical record of a location. That means that changing the length of the record over which the PDSI is calculated will change the values of the index. In other words, the index values in 2000 will be different if they are calculated using data from 1975 to 2000 than they would be if calculated using data from 1948 to 2000 . Therefore, it is important to note the period of record used in the analysis of the PDSI. The current version of the SC-PDSI supports an option that defines the calibration interval; by default, the entire historical record is used.

\section{b. Duration factors}

The PDSI is an accumulating index, that is, an index where each successive value is based on the preceding value. Specifically, any given PDSI value $X_{i}$ is a weighted sum of the previous PDSI value $X_{i-1}$, which represents the current climate trend or spell, and the current moisture anomaly $Z_{i}$, which represents how wet or dry it has been over the current period. The weights given to each of these two components are determined by the duration factors, represented by the variables $p$ and $q$ in (10):

$$
X_{i}=p X_{i-1}+q Z_{i} \text {. }
$$

In practical terms, the duration factors determine how sensitive the index is to precipitation and the lack thereof. Equation (10) is a generalization of (4) in which $p$ $=0.897$ and $q=1 / 3$. These constants directly affect the sensitivity of the index. For example, if $p$ is larger and $q$ smaller, the index will be less sensitive to sudden changes in the precipitation. Thus, the problem is to compute duration factors that are appropriate for a given location. We begin with a brief explanation of how Palmer computed the duration factors of 0.897 and $1 / 3$ used in (4). We then explain how the SC-PDSI automatically computes duration factors whenever it is computed for a given site.

\section{1) PALMER'S DURATION FACTORS}

Palmer defined his duration factors based on the linear relationship found using empirical methods between the 

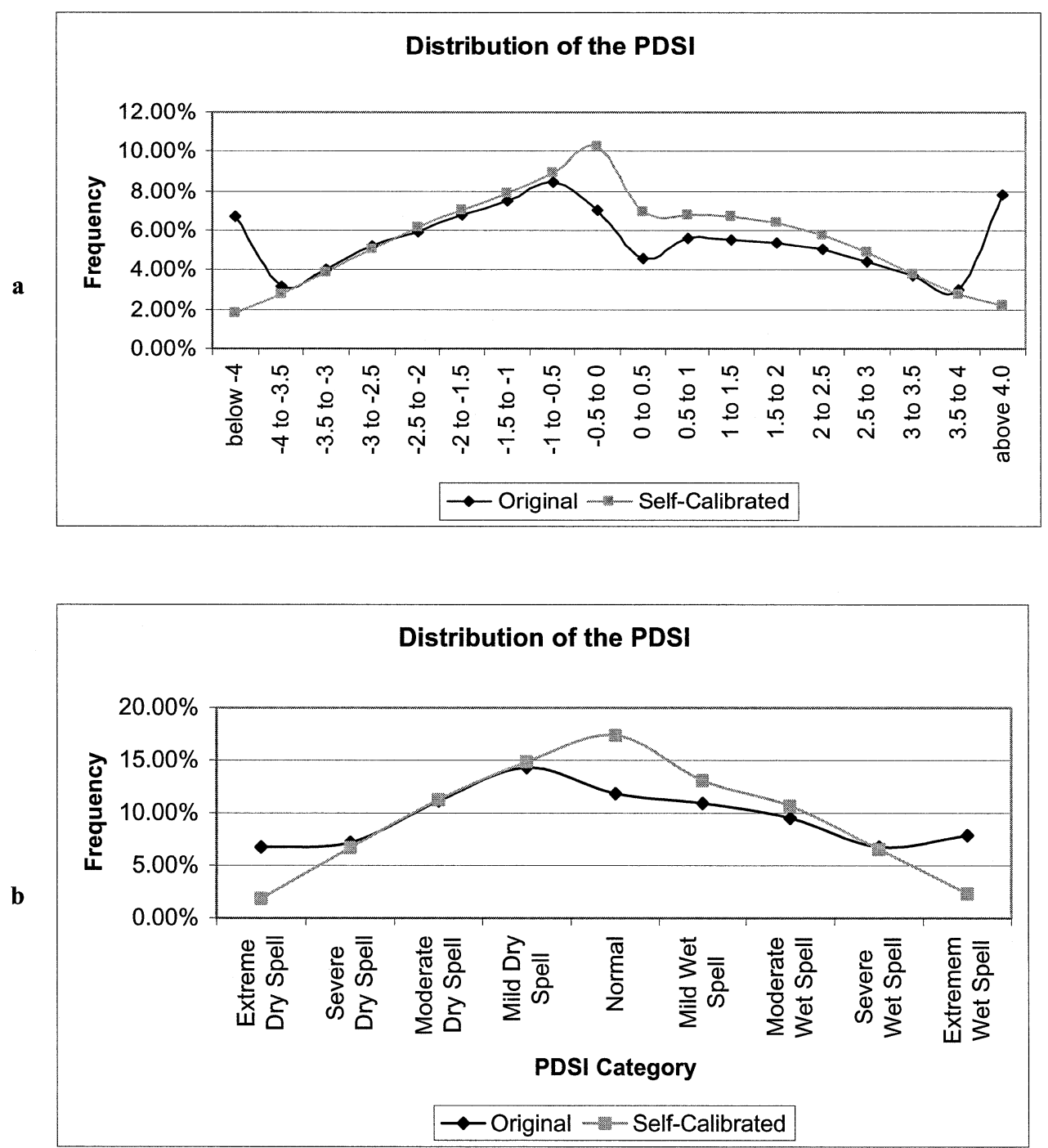

FIG. 6. Plots showing the frequency (a) over the range from -4.0 to +4.0 and (b) over the major PDSI categories of original and self-calibrated monthly PDSI values, calculated at 761 stations in CO, KS, MO, $\mathrm{NE}, \mathrm{ND}, \mathrm{SD}$, and WY.

length and severity of the most extreme droughts that he studied in Kansas and Iowa. To estimate the severity of a drought, he summed the $Z$ index over the periods of severe droughts and plotted the summation (severity) against the duration, as shown in Fig. 1. Palmer then drew the lowermost line in Fig. 1, and derived the linear relationship expressed in (11). He defined this line to represent the PDSI value of -4.0 as extreme drought. As Palmer (1965) noted, he drew this line not as a true best-fit line but rather by eye, trying to encompass the most severe drought conditions. That explains why the data from Iowa does not appear to be represented by the line. The other lines in Fig. 1 can be expressed using Eqs. (12), (13), and (14) and represent the linear relationships that Palmer defined for PDSI values of $-3,-2$, and -1 :

$$
\begin{gathered}
\text { PDSI }=-4.0 \Rightarrow \sum_{i=1}^{t} Z_{i}=-1.236 t-10.764 \\
\text { PDSI }=-3.0 \Rightarrow \sum_{i=1}^{t} Z_{i}=-0.927 t-8.073 \\
\text { PDSI }=-2.0 \Rightarrow \sum_{i=1}^{t} Z_{i}=-0.618 t-5.382 \\
\text { PDSI }=-1.0 \Rightarrow \sum_{i=1}^{t} Z_{i}=-0.309 t-2.691 \\
\qquad \sum_{i=1}^{t} Z_{i}=(0.309 t+2.691) X_{i} .
\end{gathered}
$$

For a given PDSI value $X_{t}$, these linear relationships 
TABLE 2. Summary of the PDSI analysis performed for $156 \mathrm{NE}$ weather stations.

\begin{tabular}{lcc}
\hline \hline & & $\begin{array}{c}\text { Self- } \\
\text { calibrating } \\
\text { monthly } \\
(\%)\end{array}$ \\
\hline $\begin{array}{l}\text { Original } \\
\text { monthly } \\
(\%)\end{array}$ & 12.18 & 98.08 \\
\hline Total percentage of sites in which the fre- & & \\
$\quad$ quency of extremely dry PDSI values & & \\
$\quad$ (PDSI $\leq-4.00)$ was between 1\% and 3\% & 3.21 & 94.23 \\
Total percentage of sites in which the fre- & & \\
$\quad$ quency of extremely wet PDSI values & 6.47 & 1.93 \\
$\quad$ (PDSI $\geq 4.00)$ was between 1\% and 3\% & 12.98 & 2.11 \\
Average percentage of time $\leq-4.00$ & 13.63 & 7.81 \\
Average percentage of time $\geq 4.00$ & 6.72 & 8.21 \\
Average percentage of time $\leq-3.00$ & & \\
Average percentage of time $\geq 3.00$ & & \\
\hline
\end{tabular}

can be expressed using (15), which reduces to Eqs. (11) through (14) for PDSI values of $X_{t}=-4,-3,-2$, and -1 , respectively. Equation (15) can also be used to describe the linear relationship assumed for positive PDSI values since Palmer used the same duration factors for deficit and excess moisture conditions-even though he only calibrated his index to extreme drought conditions.

Equation (15) can be further generalized to the basic slope intercept form describing the linear relationship between the summation of the $Z$ index and the current PDSI value, as shown in (16), where $m$ is the slope of the line and $b$ is the $y$ intercept:

$$
\sum_{i=1}^{t} Z_{i}=(m t+b) X_{t}
$$

As previously described, Palmer calibrated his index using the most severe droughts of various durations, which were assigned an index value of -4 . Thus, Palmer found the slope and $y$ intercept of the "best fit" line fitting the $Z$-index plots of these droughts. After finding the slope and $y$ intercept of the most severe droughts, Palmer simply divided these values by -4 (his calibration index) and multiplied them by the other indices that he used to categorize wet and dry spells (i.e., 4, 3, $2, \ldots,-3)$.

Although Palmer calibrated his index using " -4 ", droughts, the index could be calibrated to any category of drought or wet spell. The general formula for doing this is shown in (17), where $C$ represents the value of the calibration index (e.g., $-4,-3, \ldots, 4)$. Observe that with $m=-1.236, b=-10.764$, and $C=-4$, Eq. (17) reduces to Eqs. (11) through (14) for respective values of $X_{t}$ :

$$
\sum_{i=1}^{t} Z_{i}=(m t+b) \frac{X_{t}}{C} .
$$

Assuming the change between any two values of $X_{t}$ is constant for a given severity of drought (or wet spell)_ just as Palmer did, Eq. (17) can be used to derive
TABLE 3. Summary of the PDSI analysis performed for 761 stations from NE, KS, CO, WY, MO, ND, and SD.

\begin{tabular}{lcc}
\hline \hline & $\begin{array}{c}\text { Original } \\
\text { monthly } \\
(\%)\end{array}$ & $\begin{array}{c}\text { Self- } \\
\text { calibrating } \\
\text { monthly } \\
(\%)\end{array}$ \\
\hline $\begin{array}{l}\text { Total percentage of sites in which the fre- } \\
\quad \text { quency of extremely dry PDSI values }\end{array}$ & 9.33 & 85.15 \\
$\quad$ (PDSI $\leq-4.00)$ was between 1\% and 3\% & & \\
Total percentage of sites in which the fre- & 4.86 & 84.01 \\
$\quad$ quency of extremely wet PDSI values & & \\
$\quad$ (PDSI $\geq 4.00)$ was between 1\% and 3\% & & \\
Average percentage of time $\leq-4.00$ & 6.73 & 1.85 \\
Average percentage of time $\geq 4.00$ & 7.86 & 2.32 \\
Average percentage of time $\leq-3.00$ & 13.93 & 8.54 \\
Average percentage of time $\geq 3.00$ & 14.62 & 8.87 \\
\hline
\end{tabular}

a generalized version of (4) that computes the PDSI value for month $t$ :

$$
X_{t}=\left(1-\frac{m}{m+b}\right) X_{i-1}+\frac{C Z_{t}}{m+b} .
$$

Comparing (18) to (10) shows that the duration factors, as defined in (10), can be calculated using $m, b$, and $C$ in the following manner:

$$
\begin{aligned}
& p=\left(1-\frac{m}{m+b}\right) \\
& q=\frac{C}{m+b}
\end{aligned}
$$

Thus, the index can be calibrated for any dry or wet category, specified as $C$, as long as $m$ and $b$ can be computed.

Although Palmer calibrated his index with $C=-4$ and used the same duration factors for wet and dry spells, this process can be repeated to find separate duration factors for wet periods by finding the linear relationship between the intensity of extreme wet spells and their respective lengths. This is important because different locations have different sensitivities to precipitation events and some locations have different sensitivities to periods with precipitation and periods without. For example, a location that more effectively retains water in the soil will likely be more sensitive to heavy precipitation than to a lack of precipitation. Thus, two sets of duration factors, one each for dry periods and wet periods, are required for each location at which the PDSI is calculated. By automating the procedure that Palmer used to calculate his duration factors, both sets of duration factors can be calculated dynamically for any location.

\section{2) Automated calculation of the duration FACTORS}

The SC-PDSI established separate duration factors for wet and dry spells. The index duration factors are com- 

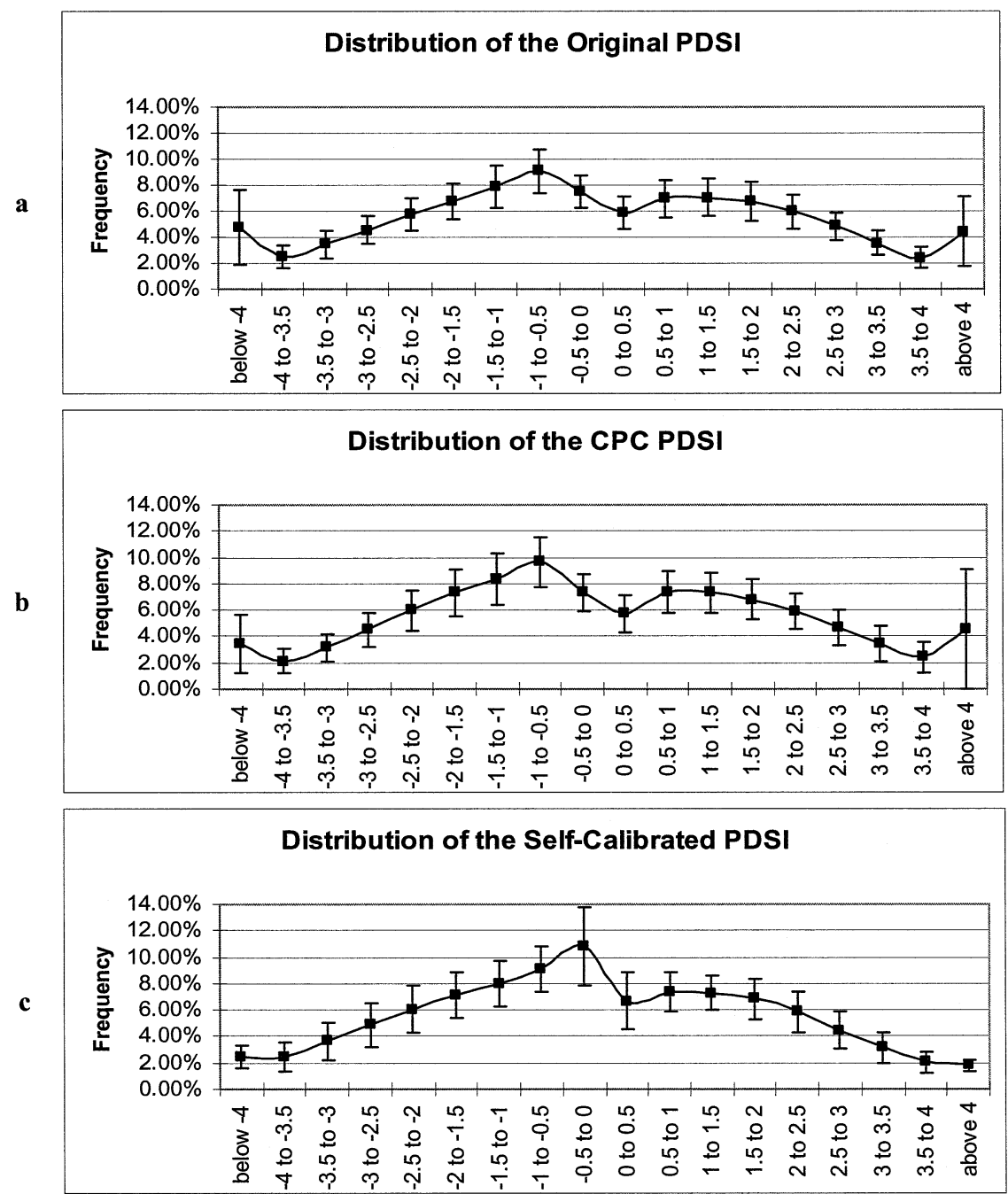

FIG. 7. Distribution plots of the mean frequency of index values from the 344 climate divisions using (a) the original PDSI, (b) the CPC's PDSI, and (c) the SC-PDSI. Error bars represent one standard deviation from the mean.

puted using the least squares method for both extremely wet and extremely dry conditions, which will give two sets of $m$ and $b$ parameters such that

$$
\sum_{i=1}^{t} Z_{i}=m t+b .
$$

Two instances of Eq. (18) are created: $X_{1}$ for dry spells and $X_{2}$ for wet spells.

Theoretically, the SC-PDSI could be calibrated to any category of drought and/or wet spell. However, calibrating to extreme wet and dry spells is the easiest to defend: 1) Palmer calibrated his index to extreme dry spells, and 2) a frequency of $1 \%-3 \%$ for extreme wet and dry conditions are defined in the literature (e.g., Guttman et al. 1992; Hayes et al. 1999), whereas there is no commonly accepted frequency of events for Palmer's other wet and dry categories.
As one would expect from a simple linear regression, there will be several points below and above a best-fit line of accumulated $Z$-index values over various lengths of time. That means that the PDSI will reach values below (above) -4.0 (4.0) on occasion. To make a line that is more representative of the most extreme periods of dryness (wetness), a new line needs to be created that is "lower" ("higher") than the true best-fit line, as shown in Fig. 2a for extreme drought conditions at Sidney, Nebraska, station $6 \mathrm{NNW}$, with climate data from 1948 to 2001.

Only the $y$ intercept was changed; the slope remains the same. Thus, by (18), decreasing the $y$ intercept results in a larger coefficient in front of $X_{i-1}$ and a smaller coefficient in front of $Z_{i}$. This means when calculating the PDSI, more weight will be given to the previous PDSI value and less to the current moisture anomaly. 



FIG. 8. Distribution plots of the mean frequency of index values in each of the main PDSI categories from the 344 climate divisions using (a) the original PDSI (b) the CPC's PDSI, and (c) the SC-PDSI. Error bars represent one standard deviation from the mean.

The change in the $y$ intercept has the effect of mapping a wider than expected range of the $Z$ index to the desired PDSI range from -4.0 to 4.0 .

There is another problem with using a simple linear regression to identify the slope and $y$ intercept of bestfit lines for extreme wet and dry conditions. Notice that neither line in Fig. 2a demonstrates a good linear correlation between all of the data points. (The correlation of the data points is -0.744922 for the initial line.) For this and many other sites, it was discovered that the accumulated $Z$ index values over various lengths of time was better represented by a nonlinear function, for example, a logarithmic function (see Wells 2002, for more details). However, a nonlinear function cannot be used with Palmer's method of calculating duration factors. Since the goal of this project was to modernize Palmer's work and not create a completely new drought index, it was decided a better approach would be to check the correlation between the data points before performing the linear least squares regression on the dataset. This is essentially what Palmer did when he drew his bestfit line.

Since Palmer placed more emphasis on short-term droughts than long-term droughts in computing his duration factors (Palmer 1965), it was decided to repeatedly throw out the point corresponding to the longest interval until a minimum threshold of \pm 0.85 for the linear correlation is attained. This threshold was deter- 




a

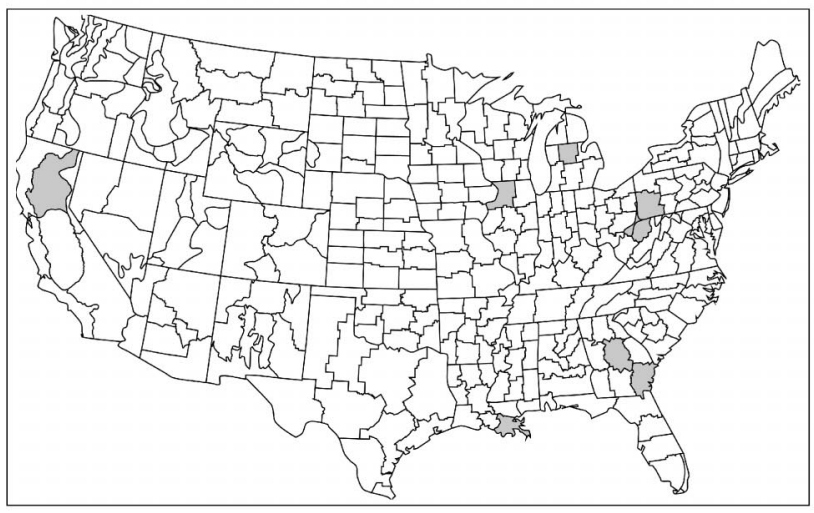

c

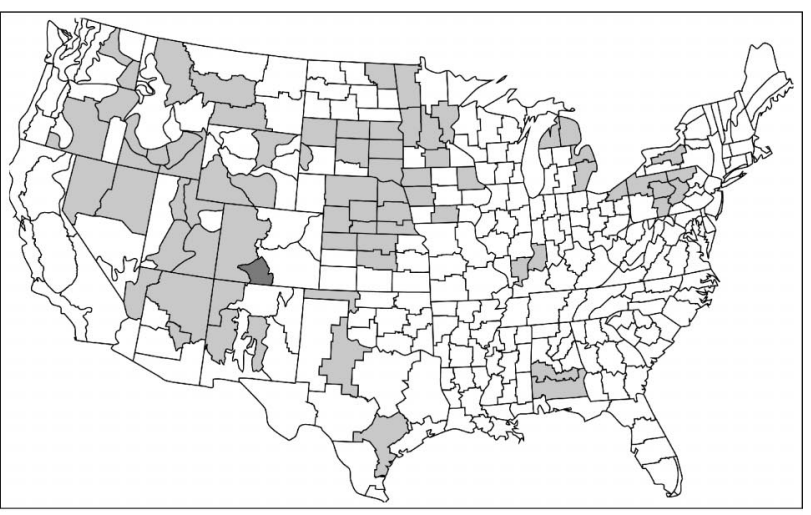

b

\begin{tabular}{|l|}
\hline $20 \%$ or greater \\
$15 \%$ to $19.99 \%$ \\
$10 \%$ to $14.99 \%$ \\
$5 \%$ to $9.99 \%$ \\
$\square 0 \%$ to $4.99 \%$ \\
\hline
\end{tabular}

FIG. 9. The frequency at which (a) the original PDSI, (b) the CPC's PDSI, and (c) the SC-PDSI programs reported an extreme drought (i.e., the percent of time the PDSI was at or below -4.0) at each climate division.

mined by trial and error to give the best results in the High Plains region. In the majority of sites with poor overall linear correlations, there was a good correlation among the first four data points. This fact led to the additional requirement of having at least four points from which to calculate the duration factors. In this example, if the last three points are ignored, the resulting correlation is -0.85983 , which is above the threshold. Performing the regression on the remaining seven points, as described previously, results in the bottom portion in Fig. 2b.

Figure $2 \mathrm{~b}$ shows the approximations to the appropriate linear relationships for both extreme wet and dry periods. Notice that, even though there was a poor correlation over the dry spells, there is a good correlation between the wet spells, and all ten points are used in the regression. The revised lines shown in Fig. 2b represent the correct linear relationships between the most extreme periods of wetness and dryness and the respective lengths. The slope and $y$-intercept terms for each line are used in Eqs. (19) and (20) to compute wet and dry duration factors for the site. The SC-PDSI program repeats this process automatically whenever it computes a PDSI value for a specified site.

\section{c. Summary}

The process of replacing all empirical constants in Palmer's procedure for calculating the PDSI has resulted in a process that is slightly more complicated than before. It is worthwhile to review the updated procedure step by step.

1) Calculate all moisture departures.

2) Calculate all moisture anomalies using $K^{\prime}$ of (1).

3) Calculate the duration factors, as described in section $3 b(2)$, using the moisture anomalies computed in step 2.

4) Calculate the PDSI using the moisture anomalies and duration factors computed in steps 2 and 3, respectively.

5) Find the 98th and $2 d$ percentile values of the PDSI.

6) Compute the new moisture anomalies using (9).

7) Calculate the SC-PDSI.

This is a more computational intensive process than Palmer's original procedure. However, the power of the current generation of computers means that the PDSI can be calculated in a matter of seconds, even for stations with over a hundred years of data. 


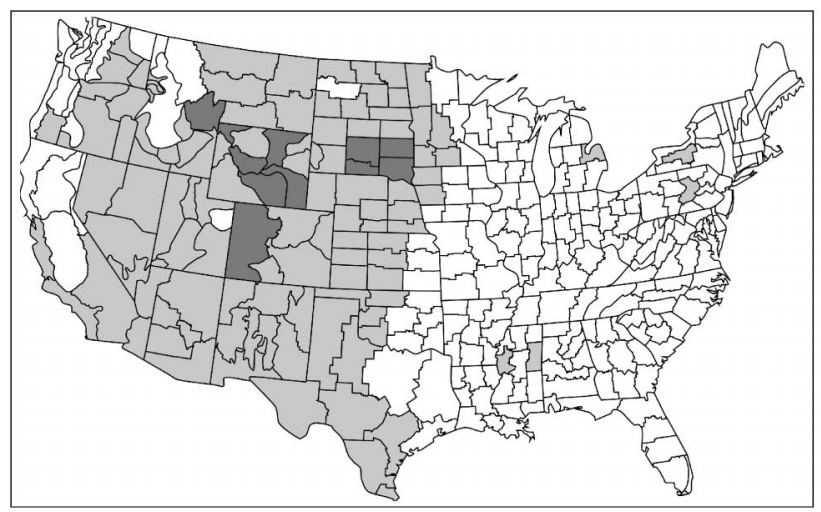

a

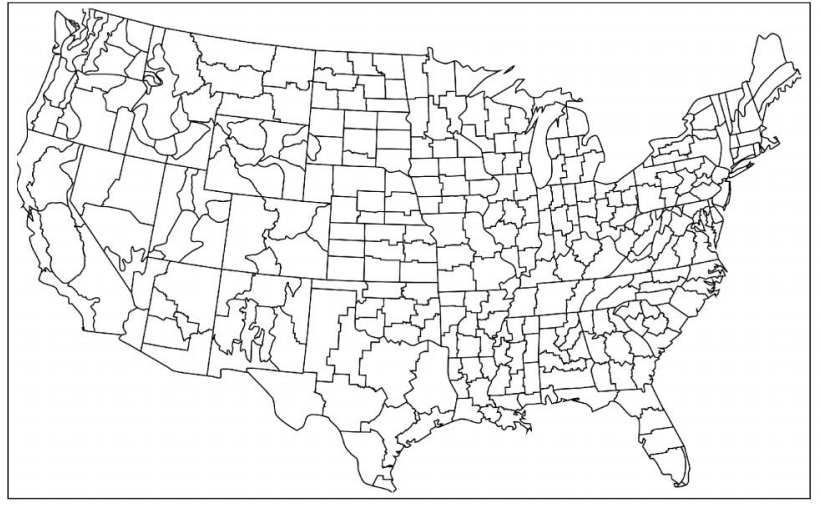

c

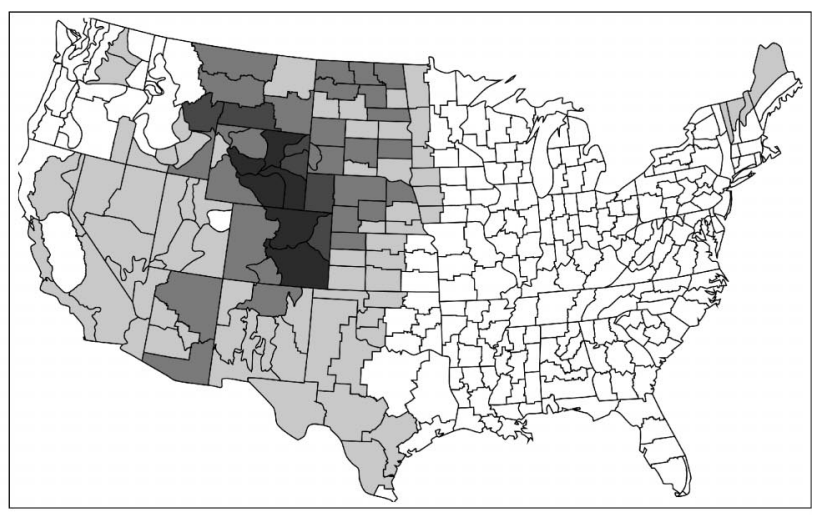

b

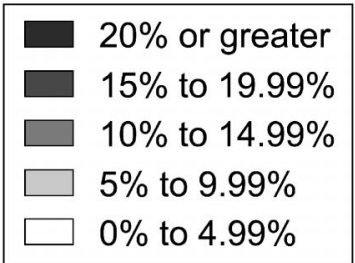

FIG. 10. The frequency at which (a) the original PDSI, (b) the CPC's PDSI, and (c) the SC-PDSI programs reported an extreme wet spell (i.e., the percent of time the PDSI was at or above +4.0) at each climate division.

Using the redefined climatic characteristic and a set of duration factors derived in the described manner to calculate the PDSI has several positive consequences:

- The range of the PDSI values is close to an expected range of -5.0 to 5.0 , where values below -4 and above 4 represent extreme conditions.

- The sensitivity of the index is based upon the local climate.

- Different sensitivity to moisture and lack of moisture.

- The PDSI can be updated at different time intervals (e.g., weekly, biweekly, monthly, etc.).

The consequences of dynamically calculating the climatic characteristic and the duration factors have the overall effect of calibrating the index based on the actual characteristics of a given location. This means the conditions of any climate should be realistically represented by the index within the definition of the PDSI. In other words, the index should show an extreme drought only when the conditions exemplify an extreme drought relative to that area and not relative to some default location. Thus, the SC-PDSI will allow more accurate comparisons between different locations and times. The SC-PDSI will also give more statistically accurate results by showing severe and extreme readings less frequently than the cur- rent implementations of the PDSI, which often show extreme readings with a frequency much higher than one would expect, as shown in section 5 .

\section{Methodology and data sources}

The goal of this work was to improve the spatial comparability of the PDSI with as little change as possible to Palmer's process. The major changes are the redefined climatic characteristic and the automatic calculation of the duration factors, both of which were based on the procedure Palmer used to derive his climatic characteristic and duration factors. No attempts were made to address other previously documented deficiencies of the PDSI [e.g., the water-balance model, Alley (1984)]. Thus, the evaluation of the SC-PDSI is limited to time series plots, analyses of the frequency of extreme conditions, plots showing the distribution of the index, and spatial comparisons of the frequency that the index is above or below a threshold.

The analysis was conducted in two stages. In the first stage, monthly PDSI values were computed for 761 individual weather stations with at least 25 serially complete years of data in the states of Colorado, Kansas, Nebraska, North Dakota, South Dakota, Wyoming, and 


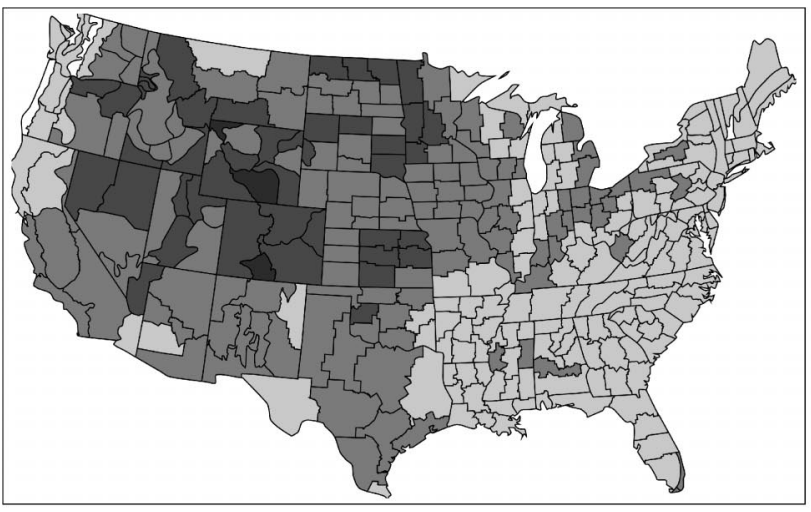

a

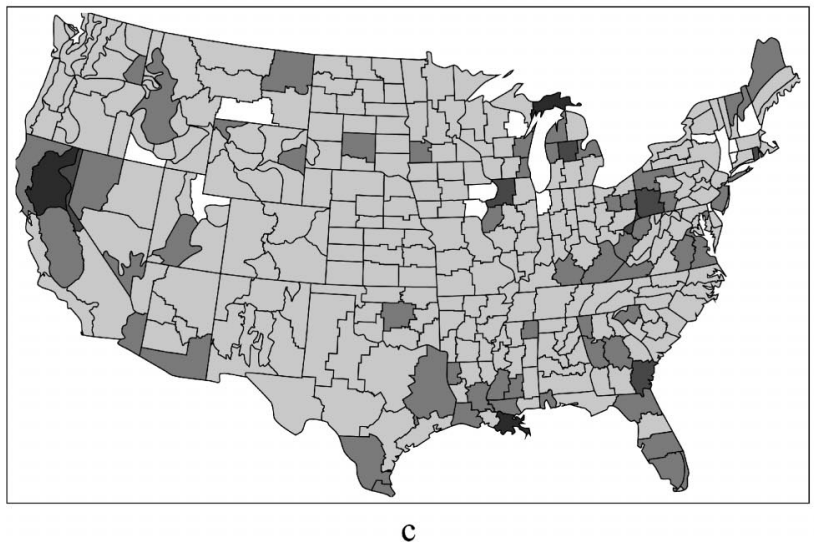

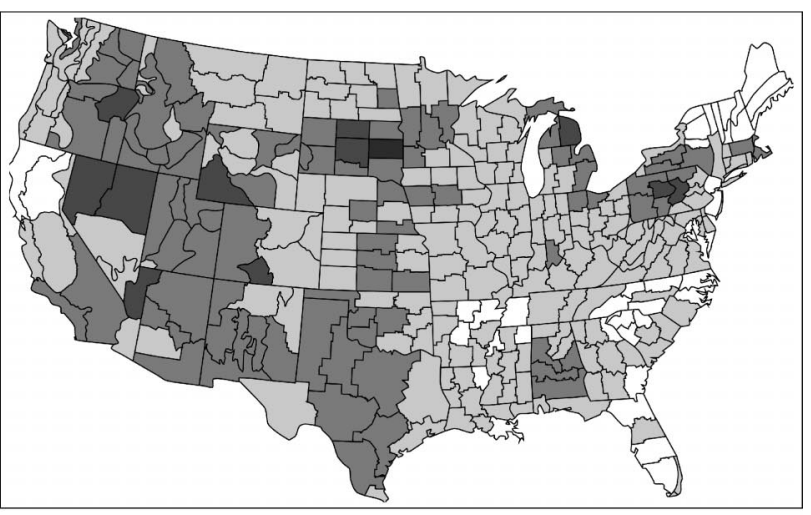

b

\begin{tabular}{|c|c|}
\hline & $\begin{array}{l}20 \% \text { or greater } \\
15 \% \text { to } 19.99 \%\end{array}$ \\
\hline & $10 \%$ to $14.99 \%$ \\
\hline & $5 \%$ to $9.99 \%$ \\
\hline & $0 \%$ to $4.99 \%$ \\
\hline
\end{tabular}

FIG. 11. The frequency at which (a) the original PDSI, (b) the CPC's PDSI, and (c) the SC-PDSI programs reported a severe or extreme drought (i.e., the percent of time the PDSI was at or below -3.0) at each climate division.

Montana. Monthly index values computed using the SCPDSI program were compared with values computed using a PDSI program developed by Karl et al. (2001) from the National Climatic Data Center (NCDC). Henceforth, the NCDC PDSI program is called the original PDSI program since Guttman et al. (1992) and Guttman $(1991,1998)$ used it in previous studies.

Temperature and precipitation data for the 761 weather stations analyzed in the first stage were retrieved from the High Plains Regional Climate Center (HPRCC 2002). For qualified stations, the PDSI was calculated using all available years of data ranging from January 1880 to July 2002. The first four years were disregarded in the analysis as Guttman (1991) recommended. To reduce the effects of backtracking, the last two years were also left out of the analysis. The AWC for each site was derived from the State Soil Geographic (STATSGO) database for the conterminous United States, which is produced and maintained by the U.S. Department of Agricultural Natural Resources Conservation Services (NRCS).

A time series plot was created for the 156 qualified stations in Nebraska and for a selected subset of stations in other states. A separate program was used to create a histogram of the PDSI values at each of the stations.
This program also calculated several statistical values such as the percentage of PDSI values that were above and below the values of $-4,-3,3$, and 4 . The results of these analyses are summarized in section 5 .

In the second stage, SC-PDSI and original PDSI monthly values were compared with monthly PDSI values reported by the National Weather Service Climate Prediction Center (CPC) for each of the 344 climate divisions of the conterminous United States from January 1895 to April 2000, with analysis performed on the $100-y r$ period from 1889 to 1998 . Monthly temperature and precipitation data were obtained from NCDC for each climate division over the interval of study (NCDC 2002a). (Data for the rest of the year 2000 were available from a different NCDC location, but for the purposes of this analysis, these data were not needed.) The latitude of the centroid of each climate division was also obtained from NCDC (NCDC 2002b). The AWC for each climate division was determined using output files of the weekly PDSI program used by the CPC, which shows the soil moisture and percent of capacity (CPC 2002).

Thus, the original and SC-PDSI programs were executed using the same data parameters that, as far as we can determine, were used by the CPC to generate their 


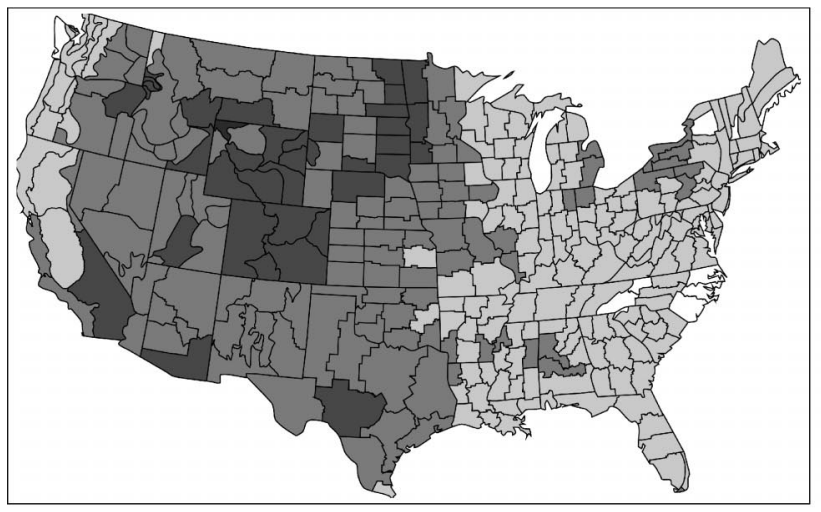

a

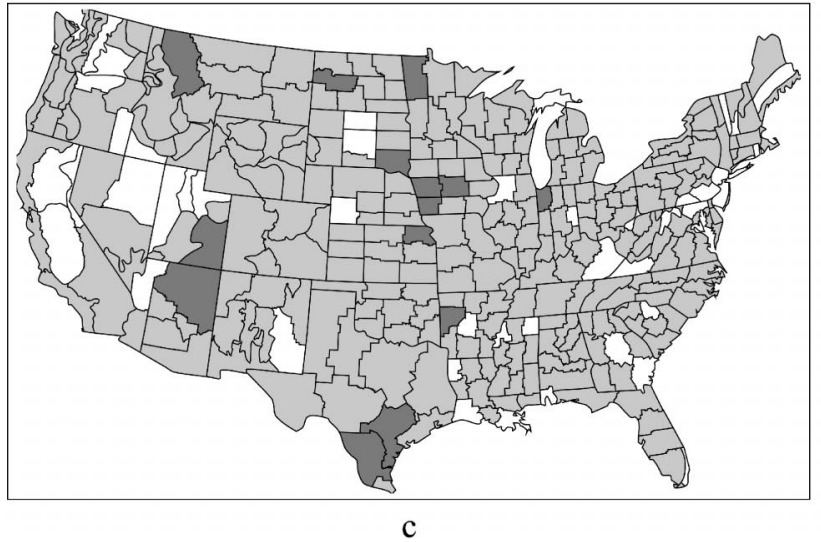

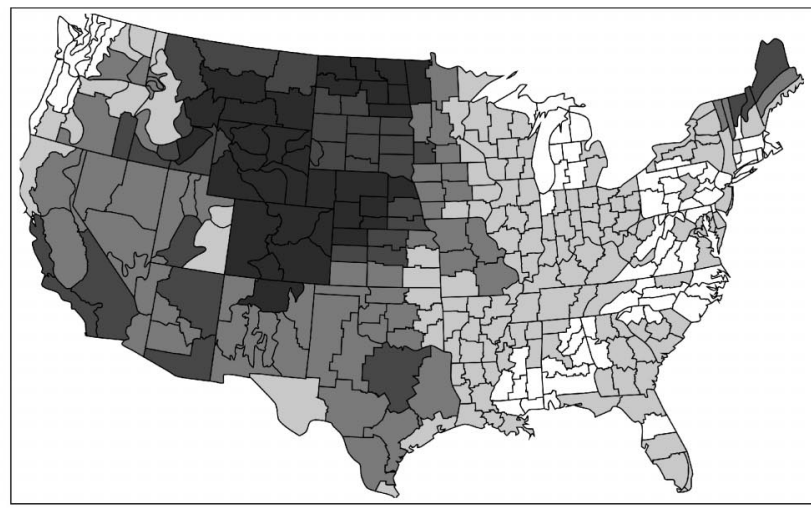

b

FIG. 12. The frequency at which (a) the original PDSI, (b) the CPC's PDSI, and (c) the SC-PDSI programs reported a severe or extreme wet spell (i.e., the percent of time the PDSI was at or above 3.0) at each climate division.

reported PDSI values. The $\mathrm{CPC}$, however, uses a different method to estimate the potential evapotranspiration and a different method to calculate $K^{\prime}$ than what is used is the original implementation of the PDSI. This dataset is serially complete and represents a large range of climates, which should give a good indication of how the three indices behave spatially.

Once the indices were obtained, the percent of time the PDSI values were in each category was calculated for each climate division. For each of the PDSI programs, a plot of the mean frequency of PDSI values in each category for the climate divisions was created. One standard deviation from the mean frequency was also computed for each category.

\section{Results}

The results of the study are organized by analysis method rather than the stages in which the study was conducted. First, time series plots comparing the original and SC-PDSI are presented for individual weather stations. Second, an analysis of the frequency of extreme conditions and plots showing the distribution of the index are presented. Third, spatial comparisons of the frequency climate division PDSI values at or below -4 , at or above 4 , at or below -3 , and at or above 3 are presented.

\section{a. Time series plots}

Time series plots of the SC-PDSI with the original PDSI are useful tools to evaluate the SC-PDSI. The time series plots will, of course, not be the identical. However, both should show some of the same trends, especially during extreme droughts and wet periods. There can be no analysis done on periods of moderation because by changing the duration factors the sensitivity of the index to precipitation was changed, which means periods of moderation may be represented very differently, especially considering backtracking.

A visual examination of the plot of the original PDSI and SC-PDSI values at 156 stations in Nebraska was conducted as a preliminary assessment of the SC-PDSI algorithm. Any large discrepancies between the two indices during periods in which either index was showing extreme values could indicate possible errors in the algorithm. Most plots of the SC-PDSI algorithm followed the original monthly version during extreme periods of drought or excessive wetness, as shown in Fig. 3a.

However, one of the 156 locations in Nebraska, Cres- 
cent Lake, showed greater deviations than expected. As shown in Fig. 3b, there are substantial differences between the original PDSI and the SC-PDSI around 1995 and again in 1999. This occurred when backtracking was triggered in the original PDSI but not in the SCPDSI. In both instances, the original PDSI soon reversed course a second time to follow the SC-PDSI. This would suggest that the backtracking may have been induced prematurely, but it is unclear which of the two indices is actually more correct during those periods of discrepancy. It should be noted, however, that the vast majority of sites resulted in time series plots that followed the same general pattern of the original PDSI, but with a PDSI range of approximately -5 to 5 , which is what one should expect from a spatially comparable index.

\section{b. Statistical analysis}

Palmer performed some statistical analysis on his index with test locations in western Kansas and central Iowa (Palmer 1965). In western Kansas, he found that drought occurred $37 \%$ of the time and wet periods $37 \%$ of the time. He explained the relatively low percentage of normal readings by the fact that "normal" weather occurs very infrequently, even at a monthly level, in western Kansas. In Iowa, drought was under way $32 \%$ of the months and a wet spell $50 \%$.

Our results are similar to Palmer's in that we found that few of the individual 761 sites examined in the High Plains states had normal weather. Plots representing histograms of original and self-calibrated PDSI values resulted in multimodal distributions for most of the sites. Figures 4 and 5 show the distributions for the Minden and Clay Center sites, respectively, in Nebraska.

The distribution of the PDSI is somewhat difficult to represent graphically. Showing the distribution over equally sized bins will usually split the normal category of PDSI values into separate bins. This results in strange curves around zero since backtracking causes more negative than positive normal values. As Table 1 shows, the ranges of the incipient wet and dry spell categories are half the size of all other categories. This prevents explicitly showing the distribution over the PDSI categories. One way to correct for this is to ignore the incipient wet and dry spells in the graphs. Each distribution is shown using both a standard representation and one over just the major PDSI categories.

The curve through the normal range of -0.5 to +0.5 is quite common in the distributions studied. The frequency of original PDSI values from -1.0 to -0.5 tends to be higher than the frequency of values from -0.5 to 0.0. Similarly, the frequency of values from 0.5 to 1.0 tends to be higher than the frequency of values between 0.0 and 0.5 . This certainly does not fit with the belief that normal values should occur more frequently than nonnormal values.

The plot in Fig. 6 shows the distribution of the orig- inal and SC-PDSI values as calculated at weather stations across Nebraska, Kansas, Colorado, Wyoming, Montana, North Dakota, and South Dakota. The original PDSI shows a lower frequency of normal values than would be expected, with the mode of the distribution being a mild dry spell. Perhaps the most interesting aspect of the distribution of the original PDSI values is the tails of the distribution. Extreme and severe droughts are reported with nearly the same frequency (approximately $7 \%$ ) while extreme wet spells are reported with greater frequency than severe set spells (approximately $8 \%$ and $7 \%$, respectively).

The SC-PDSI, on the other hand, has a near-normal distribution. The only irregularity in its distribution is that there is a slightly lower frequency of mild wet spells than mild dry spells. Moreover, the frequency of extreme conditions is approximately $2 \%$.

Table 2 summarizes the statistical analysis for the 156 Nebraska sites, and Table 3 summarizes results for all 761 sites in the seven-state study region. The performance of the SC-PDSI algorithm came closer to the expected behavior of the PDSI than the original PDSI.

The first two rows in Tables 2 and 3 are the best indicators of success in achieving spatial comparability with the SC-PDSI. Ideally, 100\% of the stations would report extreme drought (SC-PDSI $\leq-4$ ) between $1 \%$ and $3 \%$ of the time. This was the case $98.08 \%$ of the time in Nebraska and $85.15 \%$ of the time in the sevenstate High Plains region. Moreover, only 8 stations out of 761 reported extreme drought greater than $5 \%$ of the time (but less than $10 \%$ of the time). In comparison, the original PDSI reported extreme drought greater than $5 \%$ of the time in a majority of the sites, with two sites reporting extreme drought more than $25 \%$ of the time.

Figures 7 and 8 plot the mean frequency of original PDSI, SC-PDSI, and CPC reported monthly values in each category for all 344 climate divisions over the period of study. Error bars represent one standard deviation from the mean. The results are similar to that shown for the High Plains region.

Figure 8a shows that the original PDSI has an irregular distribution and appears slightly bimodal. The original PDSI has a large variance in the frequency of extreme events. Over $40 \%$ of the divisions have a frequency of extreme drought above 5\%, and 16 have a frequency above $10 \%$. Similar results can be observed for extreme wet spells.

The plot of the CPC reported PDSI values, shown in Fig. 8b, also has an irregular distribution. This distribution also appears to be slightly bimodal, but has larger standard deviations for mild spells. The standard deviations for the frequency of wet spells, especially extreme wet spells, are much larger than the standard deviations for the frequency of dry spells.

The SC-PDSI, shown in Fig. 8c has a regular distribution, with very low variance of the frequency of extreme events. The variance increases as the categories decrease in severity. Of the 344 divisions, 6 have a 
frequency of extreme droughts between $5 \%$ and $6 \%$ and 3 between $7 \%$ and $8 \%$; the rest are below $5 \%$. None of the divisions has a frequency of extreme wet spells above $4.99 \%$.

\section{c. Spatial comparisons}

A set of 12 maps was created to make spatial comparisons of the original, CPC-reported, and SC-PDSI values over the 344 climate divisions in the conterminous United States. Figure 9 shows the frequency of the original, CPC-reported, and SC-PDSI values for the climate divisions are at or below -4 . The original PDSI program reported 15 climate divisions in extreme drought at least $15 \%$ of the time, most in the western states, and 1 climate division in extreme drought more than $20 \%$ of the time. The CPC reported 71 climate divisions in extreme drought at least $5 \%$ of the time, with only 1 climate division in extreme drought more than $15 \%$ of the time. The SC-PDSI program reported all but nine climate divisions in extreme drought less than $5 \%$ of the time, with no climate division in extreme drought more than $8 \%$ of the time. The SC-PDSI program came closest to the ideal condition of all climate divisions in extreme drought less than $5 \%$ of the time.

Figure 10 shows the frequency that the original, CPCreported, and SC-PDSI values for the climate divisions are at or above 4. The original PDSI program and the CPC PDSI program performed extremely well on the eastern half of the United States, where both were near the ideal; however, they performed poorly in the western half. It appears that the CPC has calibrated their PDSI program for extreme droughts in such a way that it outperforms the original PDSI program in extremely dry conditions, but reports wet conditions in portions of the west with much higher frequency. The SC-PDSI clearly performed better than the other two versions under wet conditions with no climate divisions reporting extreme wet spells more than $4.99 \%$ of the time.

Figure 11 shows the frequency that the original, CPCreported, and SC-PDSI values for the climate divisions are at or below -3 . Overall, the SC-PDSI resulted in the most uniform reporting frequencies with $80 \%$ of the climate divisions reporting extreme or severe drought between $5 \%$ and $9.99 \%$ of the time.

Figure 12 shows the frequency that the original, CPCreported, and SC-PDSI values for the climate divisions are at or above 3. Overall, the SC-PDSI resulted in the most uniform reporting frequencies with more than $80 \%$ of the climate divisions reporting extreme or severe wet spells between $5 \%$ and $9.99 \%$ of the time.

In summary, the SC-PDSI is more spatially comparable at the climate division level than either the original PDSI program or the CPC-reported PDSI values. This result matches our spatial comparison of the original PDSI and SC-PDSI at the weather station site level in the study region.

\section{Conclusions}

The SC-PDSI addresses the recommendation made by Guttman et al. (1992) to modify the way the PDSI is computed to account for the expected variability of precipitation between locations. The SC-PDSI does this by automatically adjusting the climatic characteristic and calculating the duration factors based on the characteristics of the climate at a given location. As a result, the index performs more consistently and allows for more accurate comparisons of the index at different locations, as predicted by Guttman et al. (1992).

In a study of all the climate divisions in the conterminous United States, the SC-PDSI showed considerable improvement over the NCDC and CPC versions. It is important to note that, while the SC-PDSI is more spatially comparable than either the NCDC or CPC versions, it is not as comparable as an index computed using nonlinear methods (e.g., the Standardized Precipitation Index; McKee et al. 1993). Nonetheless, a conscious effort was made in developing the SC-PDSI to follow the linear method proposed by Palmer.

Users can download the source code to the SC-PDSI, compute original and SC-PDSI values for weather stations throughout the United States, or generate original and SC-PDSI coverage maps for all states in the conterminous United States via the National Agricultural Decision Support System (NADSS; online at http://nadss. unl.edu/).

Acknowledgments. Work was supported, in part, by grants from the National Science Foundation (EIA0091530), the USDA FCIC/RMA (02IE08310228) and the Nebraska Research Initiative. We would like to acknowledge, and thank, Bill Waltman, Jeff Peake, Mark Svoboda, Ken Hubbard, and Don Wilhite for their support and expertise.

\section{REFERENCES}

Alley, W. M., 1984: The Palmer Drought Severity Index: Limitations and assumptions. J. Climate Appl. Meteor., 23, 1100-1109.

CPC, cited 2002: Palmer Drought Severity and Crop Moisture Indices. [Available online at http://www.cpc.ncep.noaa.gov/products/ analysis_monitoring/cdus/palmer_drought/index.html.]

Guttman, N. B., 1991: A sensitivity analysis of the Palmer Hydrologic Drought Index. Water Resour. Bull., 27, 797-807.

_ 1998: Comparing the Palmer Drought Index and the Standardized Precipitation Index. J. Amer. Water Resour. Assoc., 34, 113121.

__ J. R. Wallis, and J. R. M. Hosking, 1992: Spatial comparability of the Palmer Drought Severity Index. Water Resour. Bull., 28, 1111-1119.

Hayes, M. J., M. D. Svoboda, D. A. Wilhite, and O. V. Vanyarkho, 1999: Monitoring the 1996 drought using the Standardized Precipitation Index. Bull. Amer. Meteor. Soc., 80, 429-438.

Heddinghaus, T. R., and P. Sabol, 1991: A review of the Palmer Drought Severity Index and where do we go from here? Preprints, Seventh Conf. on Applied Climatology, Dallas, TX, Amer. Meteor. Soc., 242-246. 
HPRCC, cited 2002: High Plains Regional Climate Center online weather data retrieval system. [Available online at http:// www.hprcc.unl.edu/online/home.html.]

Karl, T. R., 1983: Some spatial characteristics of drought duration in the United States. J. Climate Appl. Meteor., 22, 1356-1366.

1986: The sensitivity of the Palmer Drought Severity Index and Palmer's Z-index to their calibration coefficients including potential evapotranspiration. J. Climate Appl. Meteor., 25, $77-$ 86.

—, R. Winchell, A. McNab, and R. Heim, 2001: pdsi.f: A FORTRAN program that calculates the monthly PDSI program. National Climatic Data Center (NCDC).

McKee, T. B., N. J. Doeskin, and J. Kleist, 1993: The relationship of drought frequency and duration to time scales. Preprints,
Eighth Conf. on Applied Climatology, Anaheim, CA, Amer. Meteor. Soc., 179-184.

NCDC, cited 2002a: Time bias corrected divisional temperature-precipitation-drought index. [Available online at ftp://ftp.ncdc.noaa. gov/pub/data/cirs/drought.README.]

- cited 2002b: NOAA NCDC CIRS Climate Division dataset. [Available online at http://iridl.ldeo.columbia.edu/SOURCES/ .NOAA/.NCDC/.CIRS/.ClimateDivision/.lat/.]

Palmer, W. C., 1965: Meteorological drought. Office of Climatology Research Paper 45, Weather Bureau, Washington, D.C., 58 pp. Thornthwaite, C. W., 1948: An approach toward a rational classification of climate. Geogr. Rev., 38, 55-94.

Wells, N., 2002: Development of the self-calibrating Palmer Drought Severity Index. B.S. Honors thesis, University of NebraskaLincoln, $143 \mathrm{pp}$. 